\title{
Employee Referrals - The Best Leveraged Talent Acquisition Strategy amid Recession
}

\author{
Bhagavan Behera ${ }^{1,}$ Madhusmita Pathy ${ }^{2}$ \\ ${ }^{I}$ Department of Business Studies, Konark Institute of Science and Technology, Bhubaneswar (India) \\ ${ }^{2}$ Department of Business Studies, Konark Institute of Science and Technology, Bhubaneswar (India)
}

\begin{abstract}
In the shadow of global economic turmoil when the Governments of developed countries are resorting to adopt austerity measures to address their current economic upheaval, the modern business organizations cannot be an exception to the same. It is highly imperative for the business organizations to cut down not only the utility and operational costs but also contain the cost of recruitment as the latter is an item of expenses to be recorded on the debit side of the Profit and Loss Account and has a bearing on the profit margin. The practice of referring employees to fill a vacant position and applying for a job via a known employee has increased steadily. This paper defines the way Employee referrals have impacted the business houses as a talent acquisition strategy and how it has changed the face of headhunting industry across the globe. The purpose of this paper is to broaden the research on the recruitment practices, with focus on employee referral practices and trends across the globe, to identify what referral methods are being used and what benefits are being experienced by organizations using these methods. The paper throws a bird's eye view on the Global Employee Referral Recruitment Practices and a snail's eye view on the present scenario of Employee Referral Programs in India with special reference to the IT Sector.
\end{abstract}

Keywords: Academy Referrals, Bring Another You, Passive Candidates, Live Register, Rapid Hire

\section{Introduction}

Of late filling skill gaps by hiring employees via conventional recruitment methods has become obsolete thereby posing a striking challenge to the smart HR departments of Business Inc. MNCs are increasingly relying on alternative sources of recruitment such as employee referrals, which can efficiently be utilized to fill skill gaps. Amid enduring economic uncertainty, a good number of employers around the globe recognize the wanting of existing skilled talent as a continuing tug on business performance. Despite continued high unemployment across the globe, a majority of business houses lack skilled employees in key areas of their workforce. The biggest talent shortages appear among skilled professionals and middle management. The battle for flamboyance is more cutthroat than ever. Every company wants the best and the brightest on its team, but traditional candidate sourcing methods may not cut it anymore. Employee Referral Programs are the answer to talent shortages in the recruiting landscape.

The catchphrase and the up-to-the-minute trends in recruitment is Employee Referrals. Also known as "Word of Mouth", it is one of the internal recruitment methods in which the current employees are encouraged and rewarded for introducing suitable recruits from among the people they know. Alternatively, it can be defined as a business program that encourages current employees to suggest talented friends or contacts for open positions. Many workers are passive candidates, meaning that they are silently looking or waiting for an attractive offer. And, there's a large chance your friends are lumped into this group. The program often runs on a bonus system, where referring employees are rewarded if their candidate is chosen for a job. Employee referral programs are an ingenious way of intensifying the applicant pool. It has rather become a de rigueur recruitment tool for the companies. In this age of online social media and social networking, a referral program has even broader potential to locate qualified candidates. Referrals in the Recruitment industry are atypical pearls whose utility cannot be undermined.

\section{Nascence of Employee Referrals}

The birth of Employee referrals as a source of recruitment dates back to 55 B.C. Julius Caesar, a Roman General, who played a critical role in the events that led to the demise of the Roman Republic and the rise of the Roman Empire, offered 300 sestertii (A silver or bronze coin of ancient Rome equivalent to one fourth of a Denarius.) to any soldier recruiting another into the Roman army. This is the first known example of an employee-referral program. Given that the work had the probability to lower an individual's life expectancy or quality of life, pay had to be good to attract the best candidates. Soldiers earned 10-12 pieces of gold per year. And, it's a generous one at that: The amount represented a third of a soldier's annual pay. Benefits of working for the army included substantial grants of cash or land upon discharge, worth as much as 200 pieces of gold. Many soldiers also received sign-on bonuses of a few pieces of gold and also a share of the loot from any 
successful campaign. Even failed campaigns were rewarded. The reward was even payable on the death of new recruits within the first three months. Decimation and other factors ensured high involuntary attrition rates kept rewards high.

As wars were common, soldier turnover ratio was high, and there was a constant need for soldiers and other personnel. As a consequence, the Romans created many of the practices we have today to get the best talent. Giving the "hiring managers" the authority to pick their own employees made recruitment faster and more efficient, and also made them more responsible for their own successes or failures. Loyalty of the soldiery was transferred from Rome itself to its commanders, the men who could provide them with the loot. This made the army more effective, since the soldiers had been chosen for the tasks their commanders were entrusted with and without regard to consideration for rules imposed by bureaucrats in Rome.

\subsection{Contemporary Global Trend}

Despite the remarkable progression of talent acquisition during the past few years, employee referral programs remain the most effective recruiting tool. In fact, studies from the Society for Human Resource Management (SHRM) reveal that more than 80 percent of organizations rank these programs as the number one source of high-quality hires. That's not surprising, given the pressure being placed on recruiters to identify the right fit in an endless sea of job candidates.

A recent Towers Watson survey found that $54 \%$ of the companies that participated had problems attracting employees with critical skills, despite the high unemployment rate. Of the surveyed companies, $37 \%$ reported having trouble in hiring top-performing employees. One can overcome the shortage of top performing employees when one creates a work culture that inspires great employee referrals.

Referral programs gained momentum in the last five years as a way to avoid posting jobs that would draw hundreds or thousands of responses, swamping small human resources staffs. The data collected from various sources reveal that employee referrals have brought in $26-27 \%$ of new hires on an average, depending on the job, the employer and other factors over the last three years. Regardless of the fact that employee referral's percentile contribution to total hire fell from $28 \%$ in 2011 to $24.5 \%$ in 2012 , it still tops the external source of hire in 2012. Of the three major sources of hire during the period viz. Referrals, Career Sites and Job boards, the overall contribution of Job Boards to total hire has deteriorated considerably and it stood at $18.1 \%$ in 2012 against $24.9 \%$ in 2010. Job Boards' percentage share to total hire was $24.9 \%$ and $20.1 \%$ in 2010 and 2011 respectively. But in 2012 all did not go well with the Job Boards as it slipped from $2^{\text {nd }}$ top to third in the order of percentile contribution to total hire. The data show that Employee referrals and Career Sites have dominated the recruitment industry in 2012 as they shared together $48 \%$ of the total hire. The data also expose that employee referrals have scored over the other sources of hiring from 2010 to 2012. With the business world's shift into the digital realm well underway, there are several things companies can do to leverage employee referrals via social media. It is for sure employee referrals are still there to rule the headhunting industry in the days to come.

\subsection{Impressionable and Compelling Figures over Time Line (2010-2012)}

\begin{tabular}{|c|c|c|c|c|c|}
\hline \multicolumn{2}{|c|}{ Sources of Hire 2012 } & \multicolumn{2}{c|}{ Sources of Hire 2011 } & \multicolumn{2}{c|}{ Sources of Hire 2010 } \\
\hline Sources & \% of Total Hire & Sources & \% of Total Hire & Sources & \% of Total Hire \\
\hline Referrals & $24.5 \%$ & Referrals & $28 \%$ & Referrals & $27.5 \%$ \\
\hline Career Site & $23.4 \%$ & Job Boards & $20.1 \%$ & Job Boards & $24.9 \%$ \\
\hline Job Boards & $18.1 \%$ & Career Site & $9.8 \%$ & Career Site & $18.9 \%$ \\
\hline Direct Source & $6.8 \%$ & Direct Source & $9.1 \%$ & Direct & $5.0 \%$ \\
\hline College & $5.5 \%$ & College & $6.6 \%$ & College & $7.2 \%$ \\
\hline Rehires & $3.3 \%$ & Rehires & $4.3 \%$ & Rehires & $2.8 \%$ \\
\hline 3rd party & $3.1 \%$ & 3rd party & $2.8 \%$ & 3 rd party & $2.3 \%$ \\
\hline Social Media & $2.9 \%$ & Social Media & $3.5 \%$ & Social & NA \\
\hline Print & $2.3 \%$ & Print & $2.2 \%$ & Print & $2.0 \%$ \\
\hline Contractual & $1.5 \%$ & Contractual & $2.1 \%$ & Contractual & $2.4 \%$ \\
\hline Career Fairs & $1.2 \%$ & Career Fairs & $1.9 \%$ & Career Fairs & $1.8 \%$ \\
\hline Walk-ins & $0.3 \%$ & Walk-ins & $0.8 \%$ & Walk-ins & $0.7 \%$ \\
\hline Other & $7.2 \%$ & Other & $8.8 \%$ & Other & $4.6 \%$ \\
\hline
\end{tabular}

Table -1 Sources: CareerXRoad, SOH, Feb, 2013 
Sources of Hire 2012

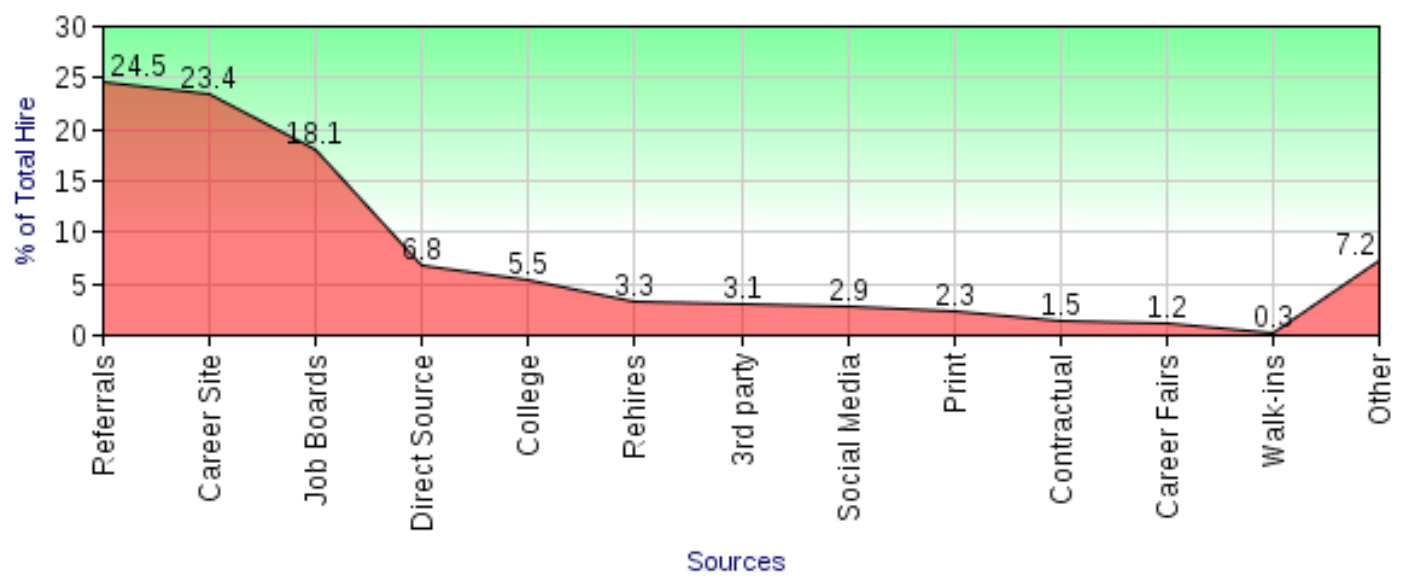

Graph -1 Sources: CareerXRoads, Sources of Hire Report, 2012 SOURCES OF HIRE 2011

Sources of Hire 2011

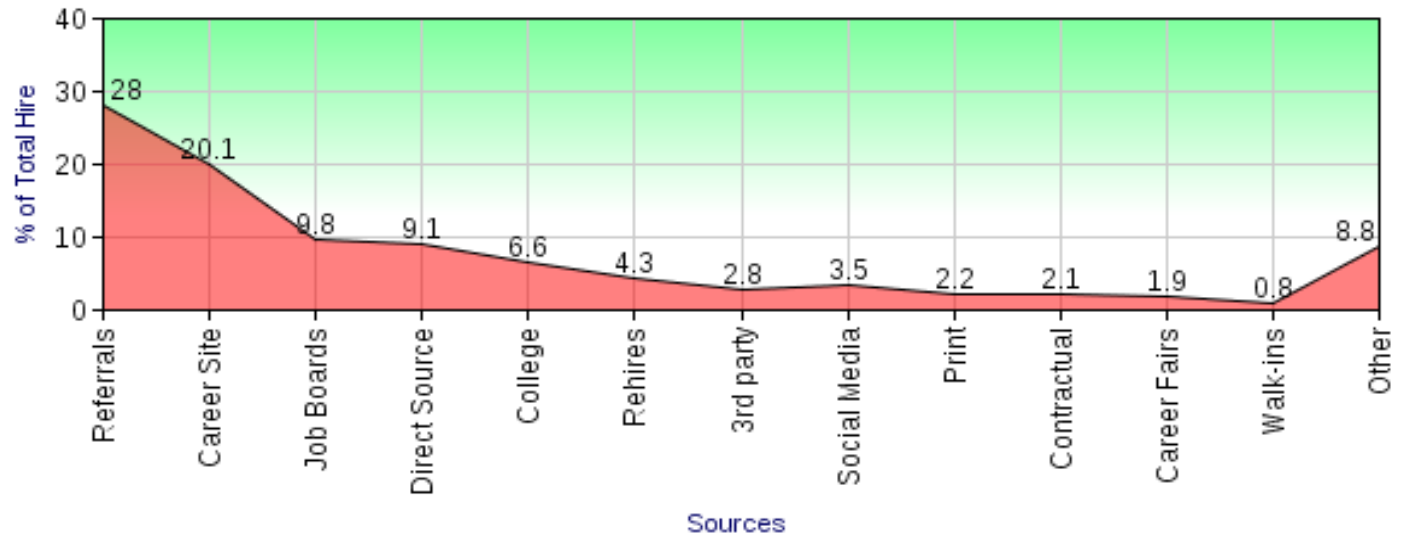

Graph-2 Sources: CareerXRoads, Sources of Hire Report, 2011

SOURCES OF HIRE 2010

Sources of Hire 2010

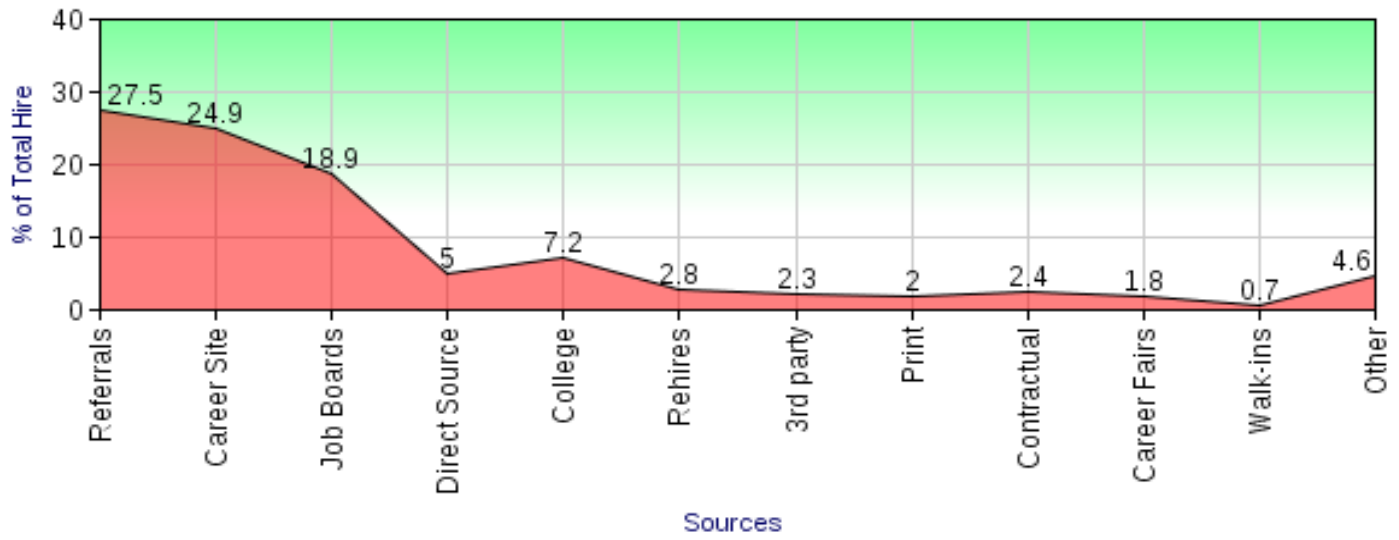

Graph-3 Sources: CareerXRoads, Sources of Hire Report, 2010 


\subsection{Referral Program Indicators:}

* 69 percent of organizations say they have a formal employee referral program at their organization (Career Builder's Referral Madness, 2010)

* Nearly 65 percent of job openings are filled through internal movement and referrals (CareerXRoads Sources of Hire Report, 2011)

- 82 percent of organizations rate employee referrals above other sources of hire for ROI (Career Builder's Referral Madness, 2010)

* 71 percent of recruiting departments are looking to social media to increase referrals (SelectMinds Why Optimizing Referrals is Critical Now, 2010)

\subsection{BEST IN THE WORLD:}

Some "best in the world" metrics to compare includes:

* Participation rate (\% of employees with at least one referral): $71 \%$-Aricent

- Percentage of all hires from referrals (with a bonus): 78\% -AmTrust

- Percentage of all hires from referrals (without paying a bonus): 70\% -AmTrust

- Employee satisfaction rate: $98 \%$-Aricent

- Percent of boomerang rehires through referrals: $72 \%$-Aricent

\subsection{SYNERGIZING VIGOR OF EMPLOYEE REFERRALS:}

- Degree - Referrals are the \#1 source in hiring volume.

- Class - Referrals are also the \#1 source for new hire quality.

- Rapidity (application-to-hire time in days) - Referrals are the \#1 fastest time to fill (29 days for referrals, 39 days for job boards, and 45 days for career sites)

- Retention (1Year) - Referrals is \#1 at 46\% retention after one year (compared to $33 \%$ from career sites and $22 \%$ from job boards).

- Retention (2 Years) - Employee referrals is \#1 at 45\% retention after two years.

* Percentage of all applicants -- Referrals is only $6.9 \%$ of applicants.

- Percentage of all hires $-46 \%$ of all hires at top performing firms are referrals, while for all firms, they range between $28 \%$ and $39.9 \%$ of all hires.

- Applicant-to-hire ratio - Referrals are \#1 and are hired at a rate of 1 out of 3 applications for topperforming firms and 1 out of 10 at average firms.

* Price tag per hire - Job boards hires cost on average $\$ 1,671$ versus referral hiring costs of $\$ 2,306$ (only $\$ 635$ more). $67 \%$ of employers and recruiters said the recruiting process was shorter and $51 \%$ said it was less expensive to recruit via referrals

- Diversity Impact - Despite the old myth that referrals have a negative diversity impact; referrals were \#1 as the "most productive" source for diversity hires, well ahead of major job boards, company affinity groups, and diversity career fairs.

* Multiplicity of Contact- The average employee will have 150 contacts on social media networks-100 employee means around 15,000 contacts (and possible candidates).

* Sales persons are the most hired position from employee referrals.

\section{Varying Employee Referral Jackpots / Bonuses / Rewards}

MNCs use a mix of monetary and non-monetary incentives for successful referrals. In addition to cash rewards for referrals, companies also offer a raffle for those employees who have made referrals. Most employees don't expect vast sums, and many are happy with other incentives, such as free travel or extra time off. A list of the top employee referral rewards offered by companies is given below:

\begin{tabular}{|c|c|}
\hline REWARD HEADS & DESCRIPTION \\
\hline SESTERTII (55 B.C) & Julius Caesar offered 300 sestertii to any soldier recruiting another into the Army \\
\hline GOLD (100 - 50 B.C) & Roman soldiers earned 10-12 pieces of gold per year as army referral bonus \\
\hline SHARE OF THE LOOT & Many soldiers also received a share of the loot from any successful campaign \\
\hline LAND/REAL ESTATE & Land / real estate was offered as referral compensation \\
\hline CASH & As always money talks \\
\hline TIME OFF & Companies give time off, ranging from an afternoon, to a day, to a week \\
\hline TRAVEL ALLOWANCE & With high petrol prices, answers included petrol paid for and train fares covered \\
\hline SPECIAL EVENT & An example being a fully paid trip to Monaco Grand Prix \\
\hline
\end{tabular}


Employee Referrals -The Best Leveraged Talent Acquisition Strategy amid Recession

\begin{tabular}{|c|c|}
\hline HOLIDAY & A week away at a choice of destination, fully paid \\
\hline RESTAURANT & A long lunch at a good restaurant to include the person referred to the company \\
\hline VOUCHERS & Retail shopping vouchers \\
\hline HEALTH SPA & Weekend away at a health spa to be pampered \\
\hline RED LETTER DAYS & Choice of certain value from the Red Letter Day website \\
\hline TRAINING COURSES & Rewarding referrals with a range of training courses they wouldn't normally go on \\
\hline WINE & Ranged from case of wine to malt whiskeys \\
\hline DAY TRIPS & This covered theme parks, visits to abroad and golf trips \\
\hline PREPAID VISA CARDS & Prepaid credit cards loaded with a pre-set amount \\
\hline PIGGY BANK & Referrals are converted on a point's basis and used at the end of the year to buy \\
\hline LUXURY GIFTS & Wide range here from watches to Tom Tom's to Cameras \\
\hline TREATS & Luxury food from deli's and fine food shops \\
\hline CHARITY & Making donations to charity for each referral brought into the company \\
\hline FLIGHTS & Vouchers for air travel. \\
\hline GYM MEMBERSHIP & Depending on level of referral, membership to a gym for a set period of time \\
\hline TICKETS & Tickets to top sporting events, concerts, shows etc. \\
\hline CAR/BIKE/IPOD & Refer a friend to and get rewarded with a car, an iPad or a motor cycle \\
\hline
\end{tabular}

\section{The Hiring Space in India}

India is a land of dissimilarity. This is perplexing to outsiders and irksome to Indians. Things are changing faster than ever before but not as fast as all of us want. One of the reasons for the contradictions is India's complexity. The Indian recruitment industry is obsessed with a numerous dynamics including the growth large conglomerates entering into new business domains and entry of multinational companies into the Indian markets. Recruiters have to muddle through with problems of access, unique expectations, and the multiple influence groups.

\subsection{SWOT Analysis of Indian Recruitment Industry}

\begin{tabular}{|c|c|}
\hline $\begin{array}{l}\text { STRENGTHS } \\
\text {-Highly skilled, English speaking workforce } \\
\text {-Cheaper workforce than their Western counterparts } \\
\text { - Abundant manpower } \\
\text {-Lower attrition rates than in the West } \\
\text {-Dedicated workforce } \\
\text {-Operational excellence } \\
\text {-Conducive business environment }\end{array}$ & $\begin{array}{l}\text { OPPORTUNITIES } \\
\text { - Client Openness for RPO model } \\
\text { - Newer sectors i.e. FDI, Retail, healthcare have capacity } \\
\text { to take large numbers } \\
\text {-India can be branded as a low-cost destination } \\
\text {-RPO for mid-size companies } \\
\text {-Global RPO back office in India } \\
\text {-Unorganized sectors moving into organized sectors }\end{array}$ \\
\hline $\begin{array}{l}\text { WEAKNESSES } \\
\text {-Highly prone to recession } \\
\text {-Incentive based payout model } \\
\text {-Slower in adopting technology and introducing newer } \\
\text { recruiting models } \\
\text {-High churn of work force } \\
\text {-Manpower shortage } \\
\text {-Anyone can start a recruiting company with limited or } \\
\text { no knowledge } \\
\text {-Absence of proper recruiting tracking systems and } \\
\text { processes at Recruiting companies }\end{array}$ & $\begin{array}{l}\text { THREATS } \\
\text {-Large MNC players targeting India job market } \\
\text { - Clients focus on reducing cost and faster turn around } \\
\text { - Client comfort with success based payout } \\
\text { - Lower entry barriers } \\
\text {-Recruiting industry is still seen as unorganized sector } \\
\text {-Large players may emerge and local players may have } \\
\text { difficulty in sustaining their business } \\
\text {-Absence of proper compliance procedures followed by } \\
\text { staffing companies }\end{array}$ \\
\hline
\end{tabular}




\section{CONTRITE STATE OF EMPLOYMENT EXCHANGES IN INDIA}

Employment exchanges have turned into barren public offices in India. In the year 2010, 969 employment exchanges spread across 28 states and seven Union Territories of India registered 6.18 million new job seekers. However, only 0.5 million ( 8.2 per cent) of these got a job.

EMPLOYMENT EXCHANGE STATISTICS - ALL INDIA - ALL CATEGORIES - 2001 - 2011

\begin{tabular}{|c|c|c|c|c|c|c|c|c|c|}
\hline \multirow{2}{*}{ 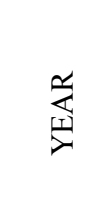 } & \multirow{2}{*}{ 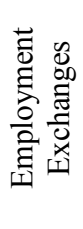 } & \multicolumn{5}{|c|}{ In Thousands } & \multirow{2}{*}{ 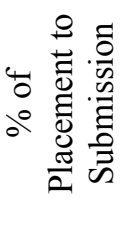 } & \multirow{2}{*}{ 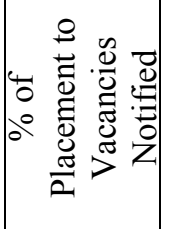 } & \multirow{2}{*}{ 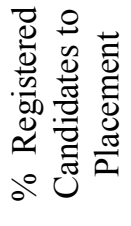 } \\
\hline & & Registration & Placement & $\begin{array}{c}\text { Vacancies } \\
\text { Notified }\end{array}$ & $\begin{array}{l}\text { Submission } \\
\text { Made }\end{array}$ & $\begin{array}{c}\text { Live } \\
\text { Register }\end{array}$ & & & \\
\hline 2001 & 938 & 5552.6 & 169.2 & 304.1 & 1908.8 & 41995.9 & 8.9 & 55.6 & 3.00 \\
\hline 2002 & 939 & 5064.0 & 142.6 & 220.3 & 1748.8 & 41171.2 & 8.2 & 64.7 & 2.81 \\
\hline 2003 & 945 & 5462.9 & 154.9 & 256.1 & 1917.3 & 41388.7 & 8.1 & 60.5 & 2.83 \\
\hline 2004 & 947 & 5373.0 & 132.6 & 274.6 & 1801.4 & 40457.6 & 7.4 & 48.3 & 2.46 \\
\hline 2005 & 947 & 5437.1 & 173.2 & 349.2 & 2402.0 & 39347.8 & 7.2 & 49.6 & 3.18 \\
\hline 2006 & 947 & 7289.5 & 177.0 & 358.2 & 3029.5 & 41466.0 & 5.8 & 49.4 & 2.42 \\
\hline 2007 & 965 & 5434.2 & 263.5 & 525.8 & 3666.1 & 39974.0 & 7.2 & 50.1 & 4.84 \\
\hline 2008 & 968 & 5315.7 & 304.9 & 571.0 & 3345.6 & 39114.9 & 9.1 & 53.4 & 5.73 \\
\hline 2009 & 969 & 5693.7 & 261.5 & 419.5 & 2589.3 & 38152.2 & 10.1 & 62.3 & 4.59 \\
\hline 2010 & 969 & 6186.0 & 509.6 & 706.9 & 3747.1 & 38826.9 & 13.6 & 72.1 & 8.23 \\
\hline 2011 & 966 & 6206.3 & 471.5 & 819.7 & 5142.9 & 40171.6 & 9.2 & 57.5 & 7.59 \\
\hline
\end{tabular}

Table 2: Sources http://dget.nic.in/publications/ees/ees2012/4\%20 Contents.pdf

Nevertheless, a closer look reveals a vicious circle. From the figures exuded in the Table -2 , it is observed that the average percentage of placement to number of students registered for the period 2001 to 2011 is 4.37(\%). During 2001 to 201163.015 million new job seekers registered themselves in the State Employment Exchanges but only 2.76 million (4.37per cent) of these got a job. The year 2010 witnessed the highest percentage of placement to number of students registered that is $8.23 \%$ whereas in 2006 the percentage of placement to number of students registered was the lowest being a mere $2.42 \%$. 


\section{Indian IT Inc and The Magnitude of Referrals}

\section{* COGNIZANT: 'BRING ANOTHER YOU' (BAY)}

Cognizant calls its employee referral program 'Bring Another You' (BAY). 'Every quarter, it has new BAY program launch, involving referral incentives such as a vacation, a brand new car or double the referral money for niche and hard-to-find skills. Cognizant's referral program contributes to over 40 per cent of the company's annual hires. Over the last three years, it has increased its recruitment through employee referrals by 10-15 per cent.

\section{* TAtA CONSUltanCY: 'RAPID HIRE'}

TATA Consultancy has adapted a marketing/CRM model for its referral program (i.e., the company offers a $24 \times 7$ referral help desk with a toll-free number). It instituted a "Rapid Hire" process where resumes were collected at referral desks that provide "on the spot" screening followed by preliminary evaluation and instant feedback. They also offer early bird \& spot prizes as well as contests between business units to foster a competitive mindset around referrals.

\section{* HCL TECHNOLOGIES LTD: 'SHARE THE JOYS OF WORKING AT HCL'}

HCL has branded its last referral campaign as 'Share the Joys of Working at HCL'. It says that candidates referred by employees tend to be of better quality because the referring employee typically screens his or her referral. Employees are not only the best brand ambassadors, but also the best equipped to ensure proper fitment between the company and the person they are referring.

\section{* WIPRO: 'WIPLINKS'}

Wipro has branded its employee referral program as 'WipLinks'. Its employee referral contributes 20-25 per cent of overall hiring. The process is fully automated - right from an employee referring a friend to receiving feedback and referral benefit. Employees can even refer friends just by sending an SMS. In 2010, Wipro doubled its referral amount to Rs 40,000.

* INFOSYS: 'REFER-A-PAL' (RAP)

Infosys believe that employees can make a good referral decision as they understand the aspirations of the candidate they refer as well as the requirements / culture of the company. During the financial year 2012, 56 per cent of Infosys' lateral hires across the globe came through employee referrals. In India, 62 per cent of its lateral hires were employed through referral programs.

\section{* Referrals Craft The Most Excellent Hires}

\section{EMPLOYEE REFERRAL BOONS}

Referrals craft the most excellent hires - a reality that comes as no shock to corporate recruiters. After all, it makes sense that the people closest to your best employees are also likely to be good employees. That's why more and more forward-thinking HR departments are trying to optimize their employee referral programs (ERPs) to yield a greater number of high-quality referrals. In fact, it's not uncommon for HR staffs to set out to increase employee referrals by 50 percent. Candidates referred by employees also tend to be of higher quality because the referring employee usually screens his or her referrals closely. After all, his or her reputation is somewhat on the line with every person he refers for a position. Referring a string of unqualified candidates reflects poorly on the referring employee's judgment, which may affect his or her own career prospects.

\section{* Referral Recruiting Lowers Recruitment Expense}

Referral recruiting provides a targeted and viral way to reach the right candidates. It empowers employee referrals and enables companies to reduce recruiting costs by involving the whole company in hiring. Study after study has found that referrals, through social networks or personal connections, produce the highest quality hires at the lowest cost in the fastest way. The reward to employees who referred your new hire is significantly lower than the cost of agency fees or from direct sourcing (about $80 \%$ less).

\section{* A Source Of passive Candidates For The Employer}

One benefit of an employee-referral program is that it can provide the employer with a source of passive candidates - those workers who are not actively seeking new jobs. This not only expands the employer's pool of potential candidates but also tends to produce higher-quality candidates.

\section{* Win-win For Everyone}

Referral recruiting is a win-win for everyone, the employer finds the right candidate, the referrer gets rewarded, the candidate gets a new job, Referral recruitment receives a small fee; all of this mainly successbased. Although this new form of recruiting has only started to gain traction, it is believed that this will be a good addition to the existing channels and it's basically a no-risk proposition for the recruiter and lets referrers convert their "social capital" to cash using the power of their social graphs. 


\section{* Referral Hires Are Fast And Last}

The average application to hire time for career sites is 45 days and 39 days for job boards. Employee referral candidates move through the hiring process $55 \%$ faster than those who came through the career site, taking only 29 days from application to hire. Referral hires also stay at a company for much longer. About $46 \%$ of referrals and $29 \%$ of those hired through career sites stay for three years or more, while only $14 \%$ of those hired from job boards stayed.

\section{* Produce fewer Non-Qualified Applicants}

It is found that referrals produce a lower percentage of "non-qualified" applicants, a characteristic that reduces the screening delay inherent in most recruiting systems and enables recruiters to focus on getting the right candidates in front of the right managers in the shortest possible time.

\section{* Better candidate assessment}

Because the individual being referred is a coworker, your employees are much more likely to thoroughly know the employee, their work, and the likelihood that they are a good fit for the position. This means that the hiring manager will have more choices and for a referred-employee candidate, they will have a second opinion on the referred employee's qualifications and fit.

\section{* Function successful across borders in global organizations}

Few recruiting programs can function across global borders without tweaks to tune the program to the local environment. Employee referral programs are one of the shining exceptions. Numerous global companies with operations in the United States, Europe, Asia, and the Middle East have deployed referral programs that function identically in nearly every location. The source has become so popular that within many companies operating in India, it has become the predominate source. The India Times reports that Indian firms often hire as many as 40 percent of their new hires via employee referral.

\section{* Reduce the burden on recruiting departments}

It is not uncommon for managed referral programs to produce more than 50 percent of an organization's total new hires. Because managed programs focus on tuning the program to produce only qualified applicants, a great deal of the labor that the recruiting department would usually expend screening and sorting applicants is eliminated.

\subsection{THE MURKY SIDE OF EMPLOYEE-REFERRAL PROGRAMS}

* An employee's social network is limited - only a small proportion of the network may be suitable for referral

* Recruiting from an employee's limited social network may compromise the diversity of the workforce

* Actively referring candidates increases an employee's workload and may be detrimental to their main responsibilities

* Lack of metrics (or only cost metrics) to enable and drive continuous improvement efforts.

- The best and most relevant candidates may not be acquainted with an existing employee of the company and therefore cannot be recruited via the referral scheme

- The primary disadvantage is that it will lead to referral spamming and flood the system with irrelevant resumes as employees are motivated due to the incentives. This creates additional pressure on the HR teams as employees will follow up on the resumes they have sent. Also, HR teams without robust screening processes or experience will find it difficult to identify the right candidates.

* Another disadvantage is that in may lead to creation of "groups" or "factions" within the organization and in the long term lead to a phenomenon called "inbreeding", where the candidates referred are virtual clones of the existing employees. This could impact the culture of the organization in a big way.

* There are some aspects of employee-referral programs that can cause problems for a company. Some are subtle, while others, like lawsuits, can literally slap a business in the face.

- Overreliance on an employee-referral program can lead to underrepresentation of certain protected groups in a company's job-applicant pool.

* Also, some competing businesses may retaliate against your company for stealing their happily employed workers via employee-referral programs.

- Excessive reliance upon an employee-referral program can lead to an inbred organization that lacks breadth of ideas, and it can foster a "stick-together" attitude that masks underlying problems in organizational behavior. Relying too heavily on an employee-referral program can also create cliques within an organization, leading to resentment and friction with other employees. 
* Some managers may have biases against employee-referral programs, feeling that referrals are favors done for shiftless in-laws rather than for the company.

* Overly restrictive bonus qualifications or excessive qualifications for employee referrals can lead to disillusionment with an employee-referral program. Under such circumstances, an employee-referral program may actually become a source of employee discontent.

\section{Conclusion and Suggestions}

Two hundred and one decade later, how diminutive stuffs have revolutionized. We're still dealing with the same problems in more or less the similar way. Triumphant conscription is a comprehensive task. It requires knowledge of sources, creativity, and a willingness to make the changes necessary. How many organizations saddle their recruiters with requirements that have little to do with the companies' purposes and goals? Hiring managers in the field are often supported by a recruitment team in a distant corporate office that has little appreciation of the conditions they face. Employee-referral bonuses are miserly and are doled out with all sorts of preconditions. The biggest changes we have seen in recruitment have been in technology, but not fundamentally in how we recruit. Yet, for all the innovations in Applicant Tracking Systems, job boards, etc., we're no better off than Caesar was in 50 B.C. Those who fall short to learn the lessons of history are condemned to repeat them.

The way companies recruit for talent has changed dramatically over the years. No one particular source able to satisfy a company's talent needs. Referrals in the Recruitment industry are atypical pearls, and it's a wonder why we don't ask for referrals more often from employees. The advent of employee referral programs helped to alleviate the talent crunch but companies continue to look for alternative cost -recruitment channel.

\section{Stimulating Applied Referrals}

While conventional referral programs depend on the erratic stream of referrals subject to the impulse of the employee population, many top programs exercise proactive components that generate flow as needed. Referral activities - visit top performers and train them through a talent detection exercise to create referrals for a particular need.

Alerts - send targeted alerts to the most pertinent employees or those who have signed up in order to make them aware of current need

Follow-up interviews - following a successful referral, interview the referring employee to thank them, find out how they sourced the hire from their network, and to ask for additional referrals.

Referral cards - offer both paper and electronic referral cards to highly visible employees in order to increase referrals.

A referral database - develops a pool of referrers who can be proactively approached. Select these individuals based on their past referrals and the likelihood that they know someone with a particular skill set.

Provide feedback on quality - provide employees with honest feedback on the quality of their referrals so they can continually improve.

\section{Shifting the Program Reach}

Academy referrals - referrals perform even better among the college population because they are well connected through social networks. An advanced program must include referrals for college hires and interns.

Managerial referrals - include executive openings and encourage executives to make referrals across the board. Come back referrals - formulate program elements that focus on top-performing employees who quit or were laid off. Corporate alumni can also be the source of referrals.

Universal referrals - do away with regional barriers to participation and open up referrals from anywhere to anywhere.

\section{Future Prospects}

Envisage being able to employ technology to scrutinize your employees' social connections and qualifications to craft relevant, data-driven recommendations about your open positions. As technology transcends, so will employee referral programs, and the businesses that will thrive are those that acclimatize to growing technology trends and embrace new ways of connecting their employees with potential talent. For example, within the last few years, recommendation engines and social media have drastically changed the way people make decisions and connect with others. While the act of making a recommendation or having a social network is not new concepts, technology has mimicked human behavior to amplify and simplify these behaviors. It has been divulged; social media sites like Facebook give employers more room to get creative in executing their employee referral program strategies, moving them to a more personalized direction than ever before. By leveraging the relationships built through social and professional networking sites, companies have access to stronger referrals and multi-pronged communications channels. 


\section{REFERENCES}

[1] Raghav Singh, History of Recruiting, part: 1, www.ere.net/2008/01/25/history-of-recruiting-part-i/

[2] The Essential History of Recruitment: From Julius Ceaser to Social Media ( Infographics) www.brandovation.co.za/?p=1054

[3] Madeline Laurano, When technology amplifies word of mouth, better hires are the result, Human Resource Outsourcing Today Vol. 10 No. 8 - October 2011

[4] Gerry Crispin \& Mark Mehler, Perception is Reality, 2013 Sources of Hire, Page 7, CareerXroads

[5] Andy Head worth, Employee Referral Reward Schemes, www.blog.sironaconsulting.com/sironasays/2008/06/top-20 employee.html

[5] Sullivan, Dr. John; "Advanced Employee Referral Programs—Best Practices You Need to Copy"; ERE.net; June 14, 2010.

[6] Irfan Abdulla, Recruitment Trends in India, www.in.reuters.com/article/2012/12/17 idINDEE8BG06S20121217

[7] Lucy Nixon, Applying SWOT Analysis to Recruitment, www.corporate-eye.com/main/applying-swot-analysis-to-recruitment

[8] Employment Exchange Statistics - All India - All Categories -2001-2011, http://dget.nic.in/publications/ees/ees2012/4\%20Contents.pdf

[9] Press releases, Employment Exchanges become Redundant, ASSOCHAM, Tuesday, March 24, 2009

[10] Newsletter, Why does referral recruitment increasingly make sense now? http://www.referralrecruitment.com/home/newsletter1

[11] T. E. Raja Simhan, Know someone, get hired, The Hindu Bisuness line,june 17, 2012

[12] Referral Madness, How Employee Referral Programs Turn Good Employees into Great Recruiters and Grow Your Bottom Line, Careerbulider, http://www.careerbuildercommunications.com/pdf/referralbook.pdf page 16 